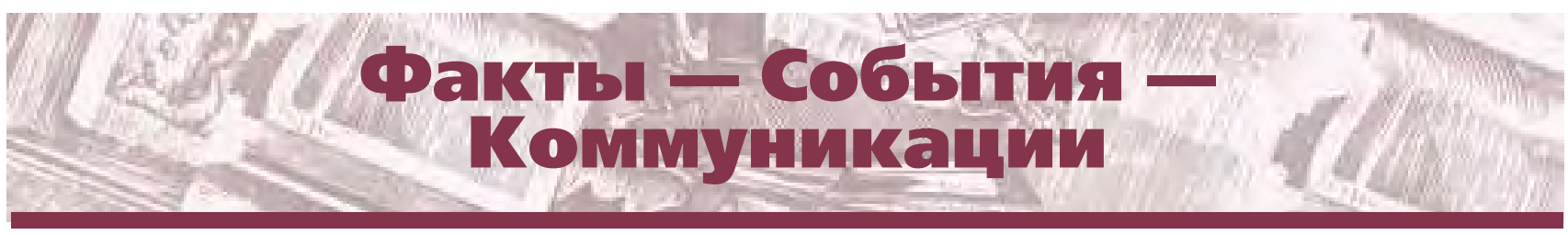

УДК 02

ББК 78.30

DOI 10.25281/0869-608X-2018-67-2-233-239

\title{
В.К. Клюев
}

\section{Николай Семенович Карташов и региональное библиотековедение}

Реферат. Представлены обзор проблематики и характеристика участников Межвузовской научнопрактической конференции, прошедшей в Московском государственном институте культуры и посвященной 90 -летию со дня рождения Н.С. Карташова.

Николай Семенович Карташов (1928-2011) - выдающийся деятель библиотечной науки и практики, известный ученый-библиотековед, крупный организатор библиотечного дела СССР, доктор педагогических наук, профессор, заслуженный работник культуры РСФСР. Впервые обосновал принцип системного подхода к изучению и организации библиотечного дела, разработал концепции регионального и сравнительного библиотековедения. В разные годы заведовал кафедрой библиотековедения Восточно-Сибирского государственного института культуры, стоял у истоков и руководил Государственной публичной научно-технической библиотекой Сибирского отделения Академии наук СССР, являлся директором Государственной библиотеки СССР им. В.И. Ленина, занимался педагогической деятельностью на кафедре библиотековедения Московского государственного института культуры.

На конференции объективировалось значение личности и научных идей Н.С. Карташова в контексте современного библиотековедения. Акцент был сделан на характеристике Н.С. Карташова как ученого, управленца и педагога, рассмотрении актуальных вопросов развития двух из основных направлений его научного наследия - регионального и сравнительного библиотековедения. В представленных участниками конференции проблемно-дискуссионных, постановочных и практико-ориентированных докладах раскрывались теоретико-методологические и методические аспекты заявленной тематики. Особый интерес вызвало осмысление в современном контексте предложенного и обоснованного Н.С. Карташовым термина «региональное библиотековедение», а также прикладные возможности использования этой актуальной концепции в отраслевом образовании и библиотечной практической деятельности в настоящее время.

Наряду с представительным очным участием, на конференции был позиционирован обширный блок стендовых докладов, в которых раскрыт вклад Н.С. Карташова в библиотечное дело и библиотековедение, в том числе методологические подходы и теоретические инструменты регионального библиотековедения, концепции библиотечного управления на основе функционального моделирования, модернизации системы территориального библиотечного обслуживания и др.

Ключевые слова: Н.С. Карташов, библиотековед, региональное библиотековедение, сравнительное библиотековедение, теория библиотечного дела, история библиотечного дела, научная конференция, Московский государственный институт культуры.

Для цитирования: Клюев В.К. Николай Семенович Карташов и региональное библиотековедение // Библиотековедение. 2018. Т. 67, № 2. C. $233-239$. DOI: $10.25281 / 0869-608 \mathrm{X}-2018-67-$ 2-233-239.

Владимир Константинович Клюев, Московский государственный институт культуры, кафедра управления информационнобиблиотечной деятельностью, заведующий

Библиотечная ул., д. 7 ,

Химки, Московская область, 141406, Россия

Московский государственный лингвистический университет, кафедра библиотечно-информационной деятельности,

профессор

Остоженка ул., д. 38, Москва, 119034, Россия

кандидат педагогических наук, профессор

E-mail: kluevvlad@yandex.ru 
$\mathrm{M}$ ежвузовская научно-практическая конференция «Региональное библиотековедение: история и современность», посвященная 90-летию со дня рождения Н.С. Карташова, прошла в Московском государственном институте культуры (МГИК) 16 марта 2018 года. Организаторы конференции - кафедра библиотековедения и книговедения и кафедра управления информационно-библиотечной деятельностью МГИК.

Имя Николая Семеновича Карташова (14 марта 1928 г. - 2 сентября 2011 г.) выдающегося деятеля библиотечной науки и практики, крупного ученого-библиотековеда и организатора библиотечного дела СССР, доктора педагогических наук, профессора, заслуженного работника культуры СССР - известно далеко за пределами Российской Федерации. Достаточно вспомнить, что Н.С. Карташов впервые обосновал принцип системного подхода к изучению и организации библиотечного дела, разработал концепции регионального и сравнительного библиотековедения, актуальные и в наше время. Отметим основные вехи профессиональной биографии юбиляра: он окончил факультет библиотековеде-

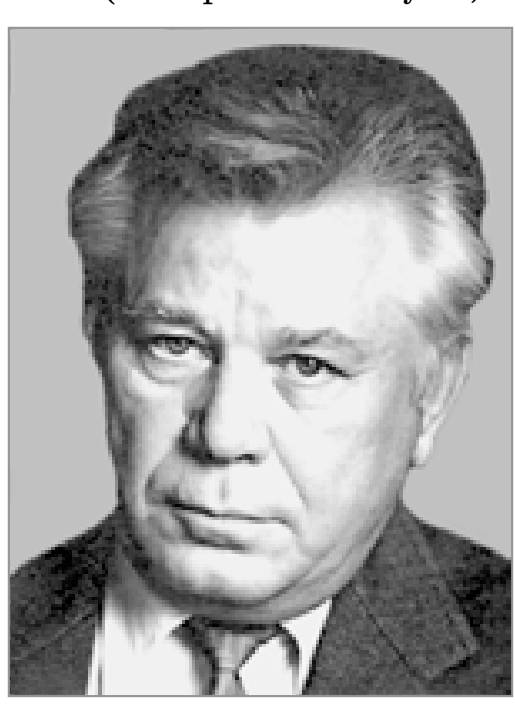

H.C. Карташов культуры СССР (1979-1990), главным редактором журнала «Советское библиотековедение» (ныне «Библиотековедение»), затем долгие годы оставался членом его редакционной коллегии.

Личность Н.С. Карташова и значимая региональная тематика определили именитый состав и широкую географию участников конференции: выступления и стендовые доклады представили 57 ведущих специалистов библиотечной науки, образования и практики из 14 регионов России (Москвы и СанктПетербурга; республик Бурятия, Крым, Мордовия и Саха (Якутия); Пермского края; Белгородской, Волгоградской, Калужской, Новосибирской, Орловской, Самарской и Тамбовской областей), а также Украины. Межвузовский статус научного форума определило представительство 13 высших учебных заведений - Белгородского, Волгоградского, Восточно-Сибирского, Московского, Орловского, Самарского, СанктПетербургского институтов культуры, Московского государственного лингвистического университета (МГЛУ), Национального исследовательского Мордовского ния (1950) и аспирантуру (1961) Московского государственного библиотечного института (в настоящее время МГИК), заведовал кафедрой библиотековедения Восточно-Сибирского государственного института культуры (Улан-Удэ, 1961-1965), руководил Государственной публичной научно-технической библиотекой Сибирского отделения Академии наук СССР (Новосибирск, 1965-1979) и Государственной библиотекой СССР им. В.И. Ленина (Москва, 1979-1990), был профессором на кафедре библиотековедения МГИК (1990-2005), председателем Всесоюзного межведомственного библиотечного совета при Министерстве

if $02(02)$

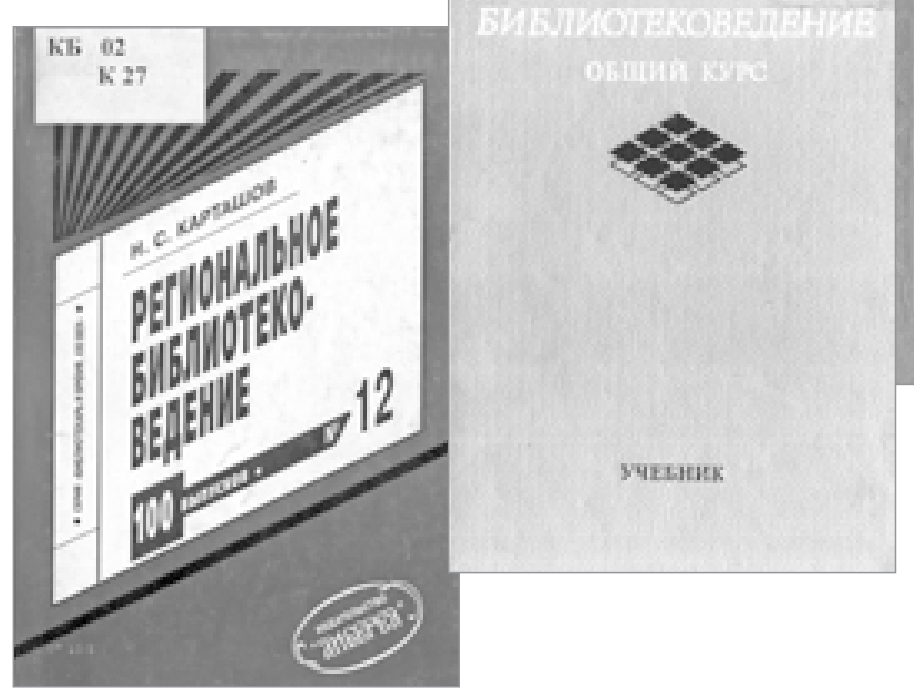
государственного университета им. Н.П. Огарёва (МГУ им. Н.П. Огарёва), Пермского национального исследовательского политехнического университета, Российского государственного аграрного университета (РГАУ-МСХА им. К.А. Ти-

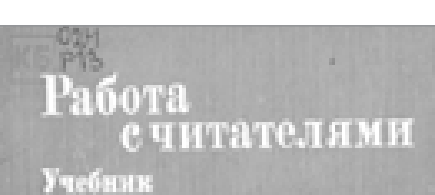
мирязева), Российской академии народного хозяйства и государственной службы при Президенте

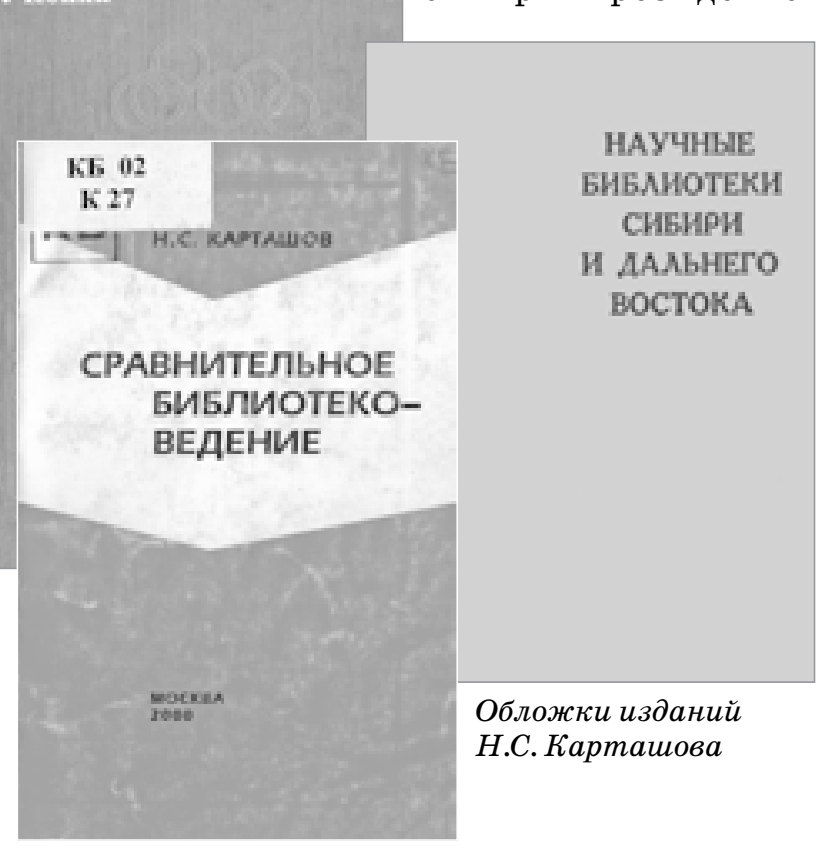


Российской Федерации, Харьковской государственной академии культуры. Библиотечную практику на конференции позиционировали: Библиотека по естественным наукам Российской академии наук (БЕН РАН), Российская государственная библиотека (РГБ), Государственная публичная историческая библиотека России (ГПИБ России), Государственная публичная научнотехническая библиотека Сибирского отделения Российской академии наук (ГПНТБ СО РАН), Российская государственная библиотека для молодежи (РГБМ), Центральная научная сельскохозяйственная библиотека; Национальная библиотека Республики Саха (Якутия); Московская областная государственная научная библиотека им. Н.К. Крупской, Калужская областная специальная библиотека для слепых им. Н. Островского, московская городская Библиотека-читальня им. И.С. Тургенева.

Информационно-библиотечный центр МГИК к конференции подготовил и оформил выставку трудов Н.С. Карташова, которая была размещена в холле перед залом заседания и вызвала активный интерес присутствующих. Отдельным блоком представлялись основные книги юбиляра [1-10].

Конференцию открыл исполняющий обязанности ректора МГИК А.С. Миронов, который поделился с собравшимися планами укрепления библиотечного образования и профильной науки в институте, проинформировал о перспективах увеличения с 2019 г. вдвое плана бюджетного приема на направление подготовки «Библиотечно-информационная деятельность» . В приветственном слове проректора по развитию, декана социально-гуманитарного факультета С.С. Ипполитова прозвучала гордость за нынешних студентов, изучающих библиотечное дело и информационные технологии в МГИК, было обращено внимание на важность разработки библиотечной политики государства.
В адрес участников конференции поступило приветствие от ГПНТБ СО РАН, в котором говорится, что Николай Семенович стоял у истоков этой Библиотеки и внес значительный вклад в ее развитие. Благодарные коллеги подготовили виртуальную выставку, посвященную Н.С. Карташову [11].

Конференция, ставившая целью объективировать значение личности и научных идей Н.С. Карташова в контексте современного библиотековедения, прошла двумя сессиями: «Н.С. Карташов - библиотекарь, ученый, управленец, педагог» и «Региональное библиотековедение: современный взгляд и проблемы», было заслушано 12 сообщений участников (в том числе из Волгограда и Калуги) и представлено для ознакомления 35 текстов стендовых докладов.

В первой части заседания собравшиеся тепло поделились воспоминаниями о Николае Семеновиче Карташове, проанализировали его научную, образовательную и административную деятельность (Ю.А. Гриханов, Библиотека-читальня им. И.С. Тургенева, Москва [12]; М.Я. Дворкина, РГБ; В.К. Клюев и Л.И. Сальникова, МГИК; В.М. Суворова, ГПИБ России [13]), охарактеризовали переданные семьей ученого в фонд РГБ профессиональную библиотеку и рукописные материалы (Л.Б. Хайцева, РГБ [14]).

Во второй части конференции рассматривались актуальные вопросы развития основных направлений научно-педагогической деятельности и творческого наследия Н.С. Карташова - регионального и сравнительного библиотековедения.

С проблемно-дискуссионным докладом «О понятии "региональное библиотековедение" " выступил Ю.Н. Столяров (Центр исследований книжной культуры, Научный и издательский центр «Наука» РАН, Москва), который высоко оценил вклад юбиляра в библиотековедческую науку и практику, но критично отнесся к предложенному им термину «региональное библиотековедение», предложив понятие «библиотечное

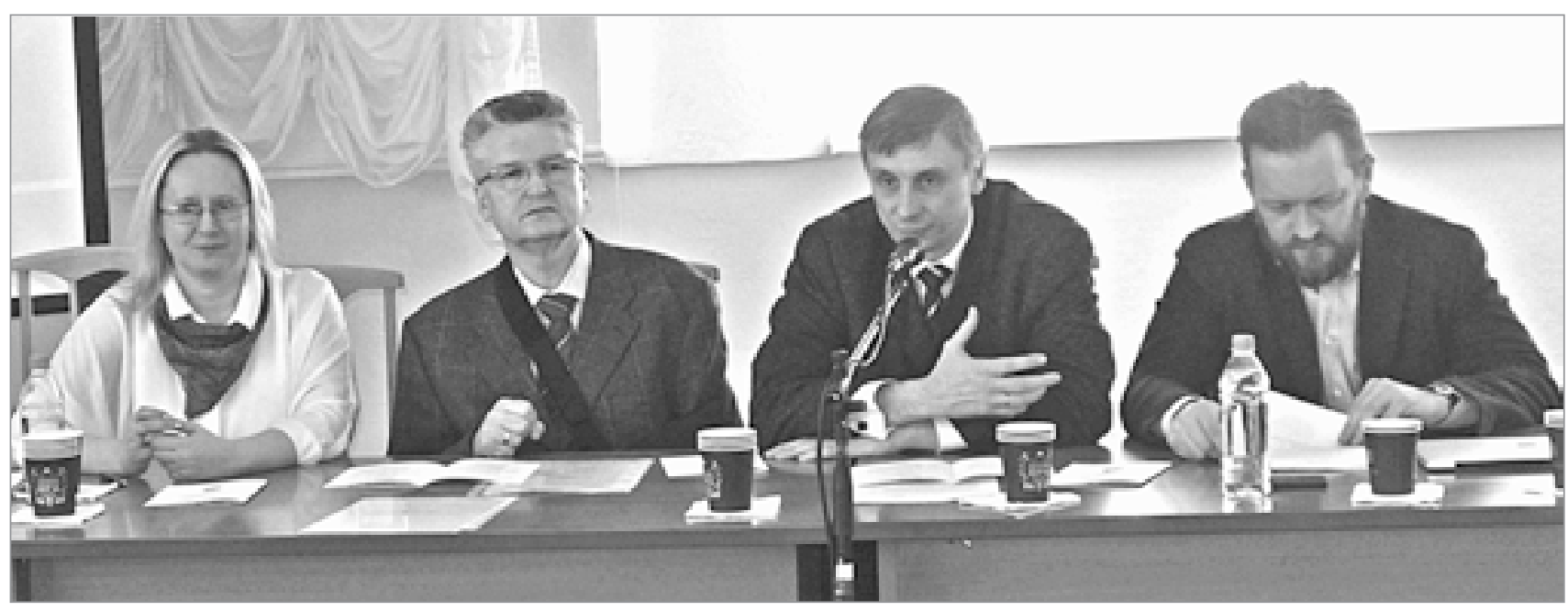

В президиуле конферениии (слева направо): Н.В. Лопатина, В.К. Клюев, С.С. Ипполитов, А.С. Миронов 
регионоведение». В рамках развернувшейся дискуссии свою точку зрения обозначили М.Я. Дворкина (РГБ), Ю.А. Гриханов (Библиотека-читальня им. И.С. Тургенева), В.А. Цветкова (БЕН РАН).

Аналитический доклад «Сравнительное библиотековедение как самостоятельная отрасль библиотечной науки» сделала Г.А. Иванова (МГИК): была дана развернутая характеристика методологии сравнительного анализа в библиотечной сфере, обоснованной Н.С. Карташовым и системно изложенной в учебнике «Сравнительное библиотековедение» [9]. Докладчик детально ответила на ряд концептуальных вопросов, заданных участниками.

Прикладные аспекты регионального библиотековедения прозвучали в выступлениях приехавших на конференцию гостей. Так, Н.С. Улановская (Волгоградский государственный институт искусств и культуры) показала значение региональной истории библиотечного дела в структуре базовой специальной подготовки бакалавров библиотечно-информационной деятельности [15], а М.П. Коновалова (Калужская областная специальная библиотека для слепых им. Н. Островского), поддерживая необходимость развития регионального библиотековедения, представила возглавляемую библиотеку как значимый и активно социально востребованный субъект культурного ландшафта Калужской области.

Обзорно-постановочный материал о сетевом взаимодействии отечественных библиотек при посредничестве электронных социальных коммуникаций изложила С.А. Чазова (МГИК), продемонстрировав, в частности, опыт интернет-представительства руководимого ею институтского Информационно-библиотечного центра. Выступавшая констатировала неоспоримую значимость в современных условиях эффективной коммуникации с пользователями и позиционирование библиотеками адекватных по навигации и информационному контенту библиотечных сайтов, а также их активности в социальных сетях.

Завершил конференцию проблемный доклад А.Ю. Единака (МГИК) «Рейтинг как инструмент регионального библиотековедения». На основе организационно-экономического анализа формализованных показателей оценки деятельности библиотек, применяемых в современной практике, сделан вывод об их несовершенстве и односторонности, ограниченности для комплексной характеристики библиотечной деятельности. В ходе обсуждения собравшиеся пришли к выводу, что в качестве объективного критерия независимой оценки работы библиотек, с учетом их территориальных особенностей, правомерно рассматривать обратную связь с пользователями, в том числе на неформальных интернет-площадках.

Среди стендовых докладов наибольший интерес вызвали: «Человек дела: о Н.С. Карташове»
(Э.Р. Сукиасян, РГБ) [16], «Библиотеки в управлении интеллектуальной собственностью региона» (Ю.С. Зубов, О.П. Неретин, Федеральный институт промышленной собственности, Москва) [17], «Современные методологические подходы и теоретические инструменты регионального библиотековедения» (Н.В. Лопатина, МГИК), «Новый формат публичной библиотеки в свете концепции “третьего места” (М.Ю. Нещерет, РГБ) [18], « $\mathrm{K}$ вопросу об изучении перспектив модернизации системы территориального библиотечного обслуживания» (В.К. Клюев, МГИК, МГЛУ), «Методологические основания применения измерительных технологий в прогнозировании кадрового обеспечения региона» (О.Б. Сладкова, РГАУ-МСХА им. К.А. Тимирязева) [19], «Региональный аспект изучения и формирования социального статуса библиотекаря» (Т.А. Неверова, Н.А. Стефановская, Тамбовский государственный университет им. Г.Р. Державина) [20], «Система библиотечно-информационного обслуживания молодежи: региональный срез» (М.П. Захаренко, РГБМ), «Услуги государственных (универсальных) библиотек субъектов Российской Федерации, представленные на созданных ими сайтах" (О.А. Кучеркова, РГБ) [21], «Стратегический менеджмент в деятельности библиотек: закономерности и тенденции развития» (А.А. Булычева, МГУ им. Н.П. Огарёва) [22], «Представление концепции библиотечного управления Н.С. Карташова на основе функционального моделирования " (И.Н. Доронина, Белгородский государственный институт искусств и культуры), «Региональное библиотековедение зарождалось в Сибири» (Е.Б. Артемьева, Н.И. Подкорытова, ГПНТБ СО $\mathrm{PAH}$ [23].

Материалы конференции опубликованы в двух номерах электронного научного журнала МГИК «Культура: теория и практика» [24].

\section{Список источников}

1. Работа с читателями : учебник / Н.С. Карташов, Б.В. Банк, Б.Г. Умнов [и др.] ; ред. В.Ф. Сахарова. 2-е изд., перераб. и доп. Москва : Книга, 1970. 352 с.

2. Карташов Н.C. Взаимодействие научных библиотек РСФСР (1917-1967 гг.) : [монография] / ГПНТБ СО АН СССР ; ред. О.С. Чубарьян. Новосибирск : Наука, 1975. $280 \mathrm{c}$.

3. Карташов Н.С. Формирование библиотечно-территориальных комплексов : [монография] / ГПНТБ СО АН СССР ; ред. Н.М. Сикорский. Новосибирск : Наука, 1978. 240 с.

4. Работа с читателями : учебник / А.Н. Ванеев, Н.С. Карташов, Б.Г. Умнов ; гл. ред. В.Ф. Сахаров. 3-е изд., испр. и доп. Москва : Книга, 1981. 296 с.

5. Библиотековедение. Общий курс : учебник / К.И. Абрамов, А.Н. Ванеев, Н.С. Карташов [и др.]; ред. К.И. Абрамова, Н.С. Карташова. Москва : Книжная палата, 1988. 224 с. 
6. Государственная библиотека СССР имени В.И. Ленина в системе библиотек : 60-80-е гг. ХХ в. : [монография] / И.П. Осипова, Н.С. Карташов, И.В. Морозова [и др.] ; Гос. б-ка СССР им. В.И. Ленина ; гл. ред. Н.С. Карташов. Москва : Книжная палата, 1989. $256 \mathrm{c.}$

7. Библиотечное обслуживание: теория и методика : учебник / А.Я. Айзенберг, Г.А. Алтухова, М.Я. Дворкина, Н.С. Карташов ; ред. А.Я. Айзенберг. Москва : Московский государственный университет культуры, 1996. 200 с.

8. Карташов Н.С. Общее библиотековедение : учебник : в 2 ч. Ч. 2. Общая теория библиотечного дела. Москва : Московский государственный университет культуры : Либерея, 1997. 256 с.

9. Карташов Н.С. Сравнительное библиотековедение : учебник. Москва : Московский государственный университет культуры и искусств : Профиздат, 2000. $336 \mathrm{c.}$

10. Карташов Н.С. Региональное библиотековедение : научно-практическое пособие. Москва : Либерея, $2004.224 \mathrm{c}$.

11. Николай Семенович Карташов - библиотечный деятель, ученый, педагог (к 90-летию) [Электронный ресурс] // ГПНТБ СО РАН : сайт. URL: http:// www.spsl.nsc.ru/news-item/nikolaj-semenovichkartashov-bibliotechnyj-deyatel-uchenyj-pedagog-k90-letiyu (дата обращения: 30.03.2018).

12. Гриханов Ю.А. Движение в будущее - линия руководителя и ученого Н.С. Карташова [Электронный ресурс] / К Культура: теория и практика : электронный научный журнал. 2018. Вып. 2 (23). URL: http://theoryofculture.ru/issues/95/1104/ (дата обращения: 30.03.2018).

13. Суворова B.М. Пока мы помним: памяти Н.С. Карташова [Электронный ресурс] // Культура: теория и практика : электронный научный журнал. 2018. Вып. 2 (23). URL: http://theoryofculture.ru/ issues/95/1107/ (дата обращения: 30.03.2018).

14. Хайщева Л.Б. Профессиональные издания и рукописные материалы Н.С. Карташова в фонде Российской государственной библиотеки [Электронный ресурс] // Культура: теория и практика : электронный научный журнал. 2018. Вып. 2 (23). URL: http:// theoryofculture.ru/issues/95/1106/ (дата обращения: 30.03.2018).

15. Улановская Н.С. Региональная история библиотечного дела в структуре базовой подготовки бакалавров библиотечно-информационной деятельности [Электронный ресурс] // Культура: теория и практика : электронный научный журнал. 2018. Вып. 2 (23). URL: http://theoryofculture.ru/ issues/95/1113/ (дата обращения: 30.03.2018).

16. Сукиасян Э.Р. Человек дела: о Н.С. Карташове [Электронный ресурс] // Культура: теория и практика : электронный научный журнал. 2018. Вып. 2 (23). URL: http://theoryofculture.ru/issues/95/1102/ (дата обращения: 30.03.2018).

17. Зубов Ю.С., Неретин О.П. Библиотеки в управлении интеллектуальной собственностью региона [Электронный ресурс] // Культура: теория и практика : электронный научный журнал. 2018. Вып. 2 (23). URL: http://theoryofculture.ru/issues/95/1110/ (дата обращения: 30.03.2018).

18. Нещерет М.Ю. Новый формат публичной библиотеки в свете концепции «третьего места» [Электронный ресурс] // Культура: теория и практика : электронный научный журнал. 2018. Вып. 2 (23). URL: http://theoryofculture.ru/issues/95/1120/ (дата обращения: 30.03.2018).

19. Сладкова О.Б. Методологические основания применения измерительных технологий в прогнозировании кадрового обеспечения региона [Электронный ресурс] // Культура: теория и практика : электронный научный журнал. 2018. Вып. 2 (23). URL: http:// theoryofculture.ru/issues/95/1121/ (дата обращения: 30.03.2018).

20. Неверова T.A., Стефановская Н.А. Региональный аспект изучения и формирования социального статуса библиотекаря [Электронный ресурс] // Культура: теория и практика : электронный научный журнал. 2018. Вып. 2 (23). URL: http://theoryofculture. $\mathrm{ru} /$ issues/95/1111/ (дата обращения: 30.03.2018).

21. Кучеркова O.A. Услуги государственных (универсальных) библиотек субъектов Российской Федерации, представленные на созданных ими сайтах [Электронный ресурс] // Культура: теория и практика : электронный научный журнал. 2018. Вып. 2 (23). URL: http://theoryofculture.ru/ issues/95/1119/ (дата обращения: 30.03.2018).

22. Бульчева A.А. Стратегический менеджмент в деятельности библиотек: закономерности и тенденции развития [Электронный ресурс] // Культура: теория и практика : электронный научный журнал. 2018. Вып. 2 (23). URL: http://theoryofculture.ru/ issues/95/1112/ (дата обращения: 30.03.2018).

23. Артельева Е.Б., Подкорытова Н.И. Региональное библиотековедение зарождалось в Сибири [Электронный ресурс] // Культура: теория и практика : электронный научный журнал. 2018. Вып. 2 (23). URL: http://theoryofculture.ru/issues/95/1109/ (дата обращения: 30.03.2018).

24. Культура: теория и практика : электронный научный журнал [Электронный ресурс] / Моск. гос. ин-т культуры. URL: http://theoryofculture.ru (дата обращения: 30.03 .2018$)$.

Иллюстративный материал предоставлен авторол статьи 


\title{
Nikolay S. Kartashov and Regional Library Science
}

\author{
Vladimir K. Klyuev, \\ Moscow State Institute of Culture, 7 Bibliotechnaya Str., Khimki, Moscow Region, 141406, Russia \\ Moscow State Linguistic University, 38 Ostozhenka Str., Moscow, 119034, Russia \\ E-mail: kluevvlad@yandex.ru
}

\begin{abstract}
The paper presents the review of the problematics and characteristics of the participants of the Interuniversity scientific and practical conference held at the Moscow State Institute of Culture and devoted to the 90th birth anniversary of N.S. Kartashov.

Nikolay S. Kartashov (1928-2011) is an outstanding figure in the library science and practice, a wellknown scientist and librarian, major organizer of librarianship in the USSR, Doctor of Pedagogical Sciences, Professor, Honoured Worker of Culture of the USSR. For the first time he substantiated the principle of systematic approach to the study and organization of librarianship and developed the concepts of regional and comparative library science.

In different years, he was in charge of the Department of library science at the East Siberian State Institute of Culture, he stood at the origins and headed the State Public Scientific and Technical Library of the Siberian Branch of the Academy of Sciences of the USSR, was the Director of the V.I. Lenin State Library of the USSR. He was engaged in pedagogical activity at the Department of Library Science of the Moscow State Institute of Culture.

The significance of the personality of N.S.Kartashov and the value of his scientific ideas in the context of the modern library science were objectified at the Conference. The emphasis was made on characterization of N.S. Kartashov as a scientist, manager and educator, on consideration of the topical issues of development of two main directions of his scientific heritage - regional and comparative library science. The problem-discussion reports, keynote presentations and practice-oriented papers presented at the Conference considered the theoretical, theory-methodological and methodological aspects of the declared subject. Of particular interest was the comprehension in the modern context of the proposed and substantiated by N.S. Kartashov the term "Regional Library Science", as well as the described application capabilities of the actual use of this relevant concept in sectoral education and library practical activities.

Along with the representative full-time participation at the conference, there was positioned an extensive block of poster presentations, which revealed the contribution of N.S. Kartashov in librarianship and library science, including methodological approaches and theoretical instruments of regional library science, the concept of library management on the basis of functional modelling, modernization of the system of territorial library services, etc.
\end{abstract}

Key words: N.S. Kartashov, Library Scientist, Regional Library Science, Comparative Library Science, Theory of Library Science, History of Librarianship, Scientific Conference, Moscow State Institute of Culture.

Citation: Klyuev V.K. Nikolay S. Kartashov and Regional Library Science, Bibliotekovedenie [Library and Information Science (Russia)], 2018, vol. 67, no. 2, pp. 233-239. DOI: 10.25281/0869-608X-2018-67-2233-239.

\section{References}

1. Sakharov V.F. (ed.) Rabota s chitatelyami: uchebnik [Working with Readers: textbook]. Moscow, Kniga Publ., 1970, $352 \mathrm{p}$.

2. Kartashov N.S. Vzaimodeistvie nauchnykh bibliotek RSFSR (1917-1967 gg.) [The Cooperation of Scientific Libraries of the Russian Soviet Federative Socialist Republic (1917-1967)]. Novosibirsk, Nauka Publ., 1975, 280 p.

3. Kartashov N.S. Formirovanie bibliotechnoterritorial'nykh kompleksov [Creating Library-Territorial Complexes]. Novosibirsk, Nauka Publ., 1978, 240 p.

4. Sakharov V.F. (ed.) Rabota s chitatelyami: uchebnik [Working with Readers: textbook]. Moscow, Kniga Publ., 1981, 296 p.

5. Abramov K.I., Kartashov N.S. (eds). Bibliotekovedenie. Obshchii kurs: uchebnik [Library Science. General Course: textbook]. Moscow, Knizhnaya Palata Publ., 1988, $224 \mathrm{p}$.

6. Kartashov N.S. (ed.) Gosudarstvennaya biblioteka SSSR imeni V.I. Lenina $v$ sisteme bibliotek: 60-80-e gg. $X X v$. [The USSR V.I. Lenin State Library in the System of Libraries: 1960s-1980s]. Moscow, Knizhnaya Palata Publ., 1989, 256 p.

7. Aizenberg A.Ya. (ed.) Bibliotechnoe obsluzhivanie: teoriya i metodika: uchebnik [Library Servicing: The Theory and Methods: textbook]. Moscow, Moskovskii Gosudarstvennyi Universitet Kul'tury Publ., 1996, $200 \mathrm{p}$. 
8. Kartashov N.S. Obshchee bibliotekovedenie: uchebnik: $v 2$ ch. Ch. 2. Obshchaya teoriya bibliotechnogo dela [General Library Science: textbook: in 2 parts. Part 2. General Theory of Library Science]. Moscow, Moskovskii Gosudarstvennyi Universitet Kul'tury Publ., Libereya Publ., 1997, 256 p.

9. Kartashov N.S. Sravnitel'noe bibliotekovedenie: uchebnik [Comparative Library Science: textbook]. Moscow, Moskovskii Gosudarstvennyi Universitet Kul'tury i Iskusstv Publ., Profizdat Publ., 2000, 336 p.

10. Kartashov N.S. Regional'noe bibliotekovedenie: nauchno-prakticheskoe posobie [Regional Library Science: scientific and practical guide]. Moscow, Libereya Publ., 2004, 224 p.

11. Nikolai Semenovich Kartashov - bibliotechnyi deyatel', uchenyi, pedagog ( $k$ 90-letiyu) [Nikolay Semyonovich Kartashov - A Librarian, Scientist, Teacher (To the 90th Anniversary)]. Available at: http:// www.spsl.nsc.ru/news-item/nikolaj-semenovichkartashov-bibliotechnyj-deyatel-uchenyj-pedagog-k90-letiyu (accessed 30.03.2018).

12. Grikhanov Yu.A. Moving into the Future - The Line of the Leader and Scientist N.S. Kartashov, Kul'tura: teoriya i praktika: elektronnyi nauchnyi zhurnal [Culture: Theory and Practice: electronic scientific journal], 2018, issue 2 (23). Available at: http://theoryofculture.ru/issues/95/1104/ (accessed 30.03.2018) (in Russ.).

13. Suvorova V.M. As Long as We Remember: To the Memory of N.S. Kartashov, Kul'tura: teoriya i praktika: elektronnyi nauchnyi zhurnal [Culture: Theory and Practice: electronic scientific journal], 2018, issue 2 (23). Available at: http://theoryofculture.ru/ issues/95/1107/ (accessed 30.03.2018) (in Russ.).

14. Khaitseva L.B. N.S. Kartashov's Professional Publications and Handwritten Materials Stored in the Russian State Library, Kul'tura: teoriya i praktika: elektronnyi nauchnyi zhurnal [Culture: Theory and Practice: electronic scientific journal], 2018, issue 2 (23). Available at: http://theoryofculture.ru/issues/95/1106/ (accessed 30.03.2018) (in Russ.).

15. Ulanovskaya N.S. The Regional History of Librarianship in the Structure of Basic Training for Bachelors of Library and Information Science, Kul'tura: teoriya i praktika: elektronnyi nauchnyi zhurnal [Culture: Theory and Practice: electronic scientific journal], 2018, issue 2 (23). Available at: http:// theoryof culture.ru/issues /95/1113/ (accessed 30.03.2018) (in Russ.).

16. Sukiasyan E.R. A Man of Action: About N.S. Kartashov, Kul'tura: teoriya i praktika: elektronnyi nauchnyi zhurnal [Culture: Theory and Practice: electronic scientific journal], 2018, issue 2 (23). Available at: http://theoryofculture.ru/issues/95/1102/ (accessed 30.03.2018) (in Russ.).

17. Zubov Yu.S., Neretin O.P. Libraries in the Region's Intellectual Property Administration, Kul'tura: teoriya i praktika: elektronnyi nauchnyi zhurnal [Culture: Theory and Practice: electronic scientific journal], 2018, issue 2 (23). Available at: http://theoryofculture.ru/ issues/95/1110/ (accessed 30.03.2018) (in Russ.).

18. Neshcheret M.Yu. A New Format of Public Library in the Light of the Conception of "Third Place", Kul'tura: teoriya i praktika: elektronnyi nauchnyi zhurnal [Culture: Theory and Practice: electronic scientific journal], 2018, issue 2 (23). Available at: http://theoryofculture. $\mathrm{ru} /$ issues/95/1120/ (accessed 30.03.2018) (in Russ.).

19. Sladkova O.B. Methodological Bases for Application of Measurement Technologies in Forecasting of the Region's Staffing, Kul'tura: teoriya i praktika: elektronnyi nauchnyi zhurnal [Culture: Theory and Practice: electronic scientific journal], 2018, issue 2 (23). Available at: http://theoryofculture.ru/ issues/95/1121/ (accessed 30.03.2018) (in Russ.).

20. Neverova T.A., Stefanovskaya N.A. The Regional Aspects of Studying and Formation of the Social Status of Librarian, Kul'tura: teoriya i praktika: elektronnyi nauchnyi zhurnal [Culture: Theory and Practice: electronic scientific journal], 2018, issue 2 (23). Available at: http://theoryofculture.ru/issues/95/1111/ (accessed 30.03.2018) (in Russ.).

21. Kucherkova O.A. The Services of State (Universal) Libraries of Subjects of the Russian Federation Presented on the Websites Created by Them, Kul'tura: teoriya i praktika: elektronnyi nauchnyi zhurnal [Culture: Theory and Practice: electronic scientific journal], 2018, issue 2 (23). Available at: http://theoryofculture.ru/ issues/95/1119/ (accessed 30.03.2018) (in Russ.).

22. Bulycheva A.A. Strategic Management in Libraries: Patterns and Development Trends, Kul'tura: teoriya i praktika: elektronnyi nauchnyi zhurnal [Culture: Theory and Practice: electronic scientific journal], 2018, issue 2 (23). Available at: http://theoryofculture.ru/ issues/95/1112/ (accessed 30.03.2018) (in Russ.).

23. Artemyeva E.B., Podkorytova N.I. The Regional Library Science Originated in Siberia, Kul'tura: teoriya i praktika: elektronnyi nauchnyi zhurnal [Culture: Theory and Practice: electronic scientific journal], 2018, issue 2 (23). Available at: http://theoryofculture.ru/issues/95/1109/ (accessed 30.03.2018).

24. Kul'tura: teoriya i praktika: elektronnyi nauchnyi zhurnal [Culture: Theory and Practice: electronic scientific journal]. Available at: http://theoryofculture. ru (accessed 30.03.2018). 